Erratum

\title{
Erratum: Ju, Z., et al. Integrative Analyses of Multilevel Omics Reveal Preneoplastic Breast to Possess a Molecular Landscape That Is Globally Shared with Invasive Basal-Like Breast Cancer (Running Title: Molecular Landscape of Basal-Like Breast Cancer Progression). Cancers 2020, 12, 722
}

\author{
Zhenlin Ju ${ }^{1,+}$, Anjana Bhardwaj ${ }^{2,+} \oplus$, Matthew D. Embury ${ }^{2}$, Harpreet Singh ${ }^{2}$, \\ Preethi H. Gunaratne ${ }^{3}$, Isabelle Bedrosian ${ }^{2, *}$ and Jing Wang ${ }^{1, *}$ \\ 1 Department of Bioinformatics and Computational Biology, Houston, TX 77030, USA; zju@mdanderson.org \\ 2 Department of Breast Surgical Oncology, The University of Texas MD Anderson Cancer Center, \\ Houston, TX 77030, USA; abhardwaj@mdanderson.org (A.B.); MDEmbury@mdanderson.org (M.D.E.); \\ s.harpreet20@gmail.com (H.S.) \\ 3 Department of Biology and Biochemistry, University of Houston, Houston, TX 77030, USA; \\ phgunara@Central.UH.EDU \\ * Correspondence: ibedrosian@mdanderson.org (I.B.); jingwang@mdanderson.org (J.W.) \\ + These two authors contributed equally.
}

Received: 24 September 2020; Accepted: 9 October 2020; Published: 20 October 2020

There is an error in the title of the paper [1]. The authors thus wish to make the following correction to this paper [1]:

Change the title from "Integrative Analyses of Multilevel Omics Reveal Preneoplastic Breast to Possess a Molecular Landscape That is Globally Shared with Invasive Basal-Like Breast Cancer (Running Title: Molecular Landscape of Basal-Like Breast Cancer Progression)" to "Integrative Analyses of Multilevel Omics Reveal Preneoplastic Breast to Possess a Molecular Landscape That Is Globally Shared with Invasive Basal-Like Breast Cancer".

The authors would like to apologize for any inconvenience caused to the readers by this change. The original article has been updated.

\section{Reference}

1. Ju, Z.; Bhardwaj, A.; Embury, M.D.; Singh, H.; Gunaratne, P.H.; Bedrosian, I.; Wang, J. Integrative Analyses of Multilevel Omics Reveal Preneoplastic Breast to Possess a Molecular Landscape That Is Globally Shared with Invasive Basal-Like Breast Cancer (Running Title: Molecular Landscape of Basal-Like Breast Cancer Progression). Cancers 2020, 12, 722. [CrossRef] [PubMed]

Publisher's Note: MDPI stays neutral with regard to jurisdictional claims in published maps and institutional affiliations.

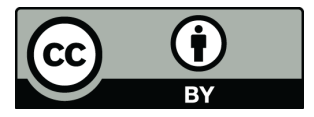

(C) 2020 by the authors. Licensee MDPI, Basel, Switzerland. This article is an open access article distributed under the terms and conditions of the Creative Commons Attribution (CC BY) license (http://creativecommons.org/licenses/by/4.0/). 